Удк $547.327+547.221$

\title{
СИНТЕЗ N-ФЕНИЛИМИДОВ ПОЛИФТОРАЛКИЛОВЫХ ЭФИРОВ МАЛЕОПИМАРОВОЙ КИСЛОТЫ ${ }^{*}$
}

\author{
(C) Л.М. Попова ${ }^{*}$, В.А. Иванова ${ }^{1}$, С.В. Вериилов ${ }^{2}$ \\ ${ }^{1}$ Санкт-Петербургский государственный университет промышленных \\ технологий и дизайна, Высшая школа технологии и энергетики, ул. Ивана \\ Черных, 4, Санкт-Петербура, 198095 (Россия), e-mail: lorapopova@mail.ru \\ ${ }^{2}$ Научно-исследовательский институт синтетического каучука \\ им. акад. С.В. Лебедева, ул. Гапсальская, 1, Санкт-Петербург, 198035 (Россия)
}

Для решения задачи по комплексной переработке растительного сырья, в частности, талловой канифоли, нами проведены исследования по синтезу новых полифторзамещенных малеимидов. Как известно, имиды малеопимаровой кислоты представляют собой перспективный класс органических соединений для фармакологии, сельского хозяйства, химии полимеров и некоторых других технических отраслей. Введение фторуглеродного фрагмента часто придает химическим соединениям ряд специфических свойств: высокую поверхностную активность, устойчивость в агрессивных средах, олеои гидрофобность. В работе представлены результаты экспериментов по синтезу новых N-фенилимидов полифторалкиловых эфиров малеопимаровой кислоты (МПК) взаимодействием соответствующих монозамещенных полифторсодержащих малеопимаратов с анилином при кипячении в толуоле в течение 10-16 ч (выход от 40 до 52\%). Исходный Nфенилимид малеопимаровой кислоты был получен двумя методами: по реакции Дильса-Альдера из абиетиновой кислоты и $\mathrm{N}$-фенилмалеимидом в расплаве при катализе серной кислотой (выход 40\%) и нагреванием (МПК) с анилином в толуоле (выход 80\%). Для синтеза полифторзамещенных $\mathrm{N}$-фенилимидов малеопимаратов использовали 2,2,3,3,4,4,5,5-октафторамиловый и 2,2,3,3,4,4,5,5,6,6,7,7-додекафторгептиловый эфиры, полученные этерификацией МПК спиртами-теломеров (n=2 и 3) в условиях кислотного катализа с выходом 70\%. В процессе экспериментов выявлено, что сложноэфирные связи довольно устойчивы - образование N-фенилимида малеопимаровой кислоты отмечалось (по данным ТСХ) при длительной обработке реакционной массы (свыше 11 ч). Синтезированные вещества исследованы методами УФ-, ИК-, ЯМР ${ }^{1} \mathrm{H}$ и ${ }^{19} \mathrm{~F}$-спектроскопии.

Ключевые слова: $N$-фенилимиды, абиетиновая кислота, малеопимаровая кислота, $N$-фенилимиды полифторалкиловых эфиров малеопимаровой кислоты.

\section{Введение}

Тенденцией последних нескольких десятилетий являются интенсивные исследования продуктов так называемой «зеленой химии». Эти разработки касаются уточнения состава растительного сырья, методов разделения компонентов, химической модификации таких компонентов. В результате постоянно расширяется как перечень практически важных химических продуктов переработки растительного сырья (возобновляемых ресурсов), так и спектр областей их применения.

Трициклические дитерпеновые кислоты ряда абиетана составляют значительную часть канифоли - побочного продукта ЦБП. Огромные объемы образования канифоли при переработке древесины представляют перспективную сырьевую базу.

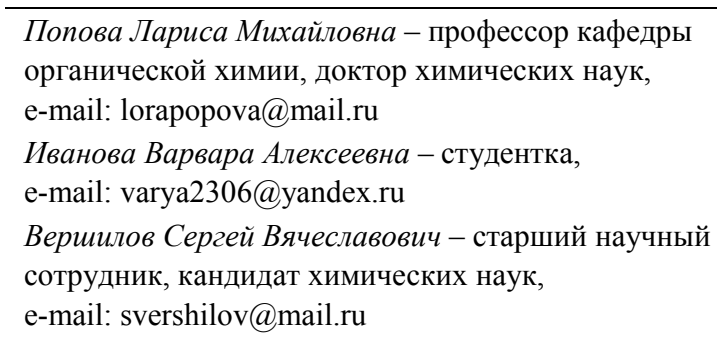

Производные малеопимаровой кислоты (МПК) активно изучаются в последние десятилетия и находят применение в различных областях производства. Наряду с традиционным использованием в лакокрасочной и ЦБП $[1,2]$ новые направления связаны с такими отраслями, как

\footnotetext{
*Данная статья имеет электронный дополнительный материал (приложение), который доступен читателям на сайте журнала. DOI: 10.14258/jcprm.2019023999s.

* Автор, с которым следует вести переписку.
} 
электроника [3], биология и медицина [4]. Производные МПК также рассматриваются в качестве ПАВ [5]. Имиды МПК предложены в качестве фунгицидов и стимуляторов рост пролонгированного действия [6]. Сообщалось, что $N$-(2-метил)- $\alpha$-нафтилимид МПК и ее метиловый эфир проявляют ингибирующее действие на рост раковых клеток [7]. Производные имидов малеопимаровой кислоты повышают термостойкость и ударопрочность полимеров [8], могут использоваться для разработки светочувствительных материалов [9].

Существенную часть канифоли и продуктов ее модификации используют в процессах изготовления бумаги, картона и прочих волокнистых материалов. Эти компоненты выполняют, прежде всего, функцию связующих агентов. Другая функция - защитная - повышение устойчивости поверхности материала к воздействию воды и масел. Как известно, лучшей гидро- и олеофобизирующей способностью обладают вещества, содержащие в своей структуре фторированные фрагменты [10].

Получение имидов МПК возможно осуществить непосредственно из живицы или канифоли по реакции диенового синтеза с $\mathrm{N}$-замещенными малеимидами [11].

Другой способ - конденсация МПК и соединения с аминогруппой - более предпочтителен и открывает большие синтетические возможности. В зависимости от температуры и природы аминопроизводного реакции могут протекать по нескольким направлениям. Так, при $80-150{ }^{\circ} \mathrm{C}$ и эквимольном соотношении реагентов в ледяной уксусной кислоте, 18 ч [12], толуоле, 16 ч [13, 14] образуются преимущественно моноимиды. Также сообщалось [15] о получении серии имидов метилового эфира МПК с высокими выходами при двукратном избытке амина в ДМСО в интервале температур от 120 до $160{ }^{\circ} \mathrm{C}$ за 30-40 мин под действием ультразвуковых колебаний. В случае использования диаминов и двукратном избытке кислоты происходит образование диимидов $[16,17]$, а увеличение температуры более $200^{\circ} \mathrm{C}$ приводит к поликонденсации с образованием полиамидина. Применение аминоспиртов в этих же условиях ведет к получению полиимидоэфиров [16].

\section{Экспериментальная часть}

Чистоту исходных и полученных соединений контролировали методом ТСX на пластинках Сорбфил, элюент: гексан - дихлорметан - ацетон $(1: 1: 0,2)$. УФ спектры веществ, растворенных в хлористом метилене, получены на спектрофотометре СФ-2000 при концентрации соединений $10^{-4}$ моль/см ${ }^{3}$, толщина поглощающего слоя -1 см. Спектр ЯМР ${ }^{1} \mathrm{H}$ и ${ }^{19} \mathrm{~F}$ регистрировали на приборе Bruker $500 \mathrm{c}$ рабочей частотой $400 \mathrm{MГц}$ (370 МГц - для ${ }^{19} \mathrm{~F}$ ) в растворе $\mathrm{CDCl}_{3}$; внешний стандарт $-\mathrm{CCl}_{3} \mathrm{~F}$.

ИК-спектры регистрировали на приборе Shimadzu IRPrestige-2 в тонком слое на стеклах $\mathrm{KBr}$ (в растворе $\mathrm{CCl}_{4}$ ). Очистку растворителей (толуола, ДМФА) осуществляли известными методами [18].

В работе были использованы $N$-фенилмалеимид (I) (т. пл. $88-90^{\circ} \mathrm{C}$ ), анилин (т. кип. $184-185^{\circ} \mathrm{C}$ ) [18], абиетиновая кислота (II) (т. пл. $165-167^{\circ} \mathrm{C}$ ), выделенная из талловой канифоли ГОСТ 14201-83 известным методом [19], малеопимаровая кислота (III) (т. пл. 216-217 ${ }^{\circ} \mathrm{C}$ ), синтезированная по методу [20], 2,2,3,3,4,4,5,5-октафтор-1-пентанол (а) (т. кип. $141^{\circ} \mathrm{C}$ ) и 2,2,3,3,4,4,5,5,6,6,7,7-додекафтор-1-гептанол (б) (т. кип. $171,2{ }^{\circ} \mathrm{C}$ ) [21]. Получение $2,2,3,3,4,4,5,5$-октафторамилового (Va) и 2,2,3,3,4,4,5,5,6,6,7,7-додекафторгептилового (Vб) эфиров МПК проводили аналогично [22] при эквимольном отношении реагентов.

$N$-фенилимид малеопимаровой кислоты (IV) (способ 1). К 5 г (16,5 ммоль) абиетиновой кислоты (II) добавили 2.85 г (16,5 ммоль) ФМИ (I) и нагревали в течение 2 ч при $90{ }^{\circ} \mathrm{C}$, после чего температуру повысили до $100{ }^{\circ} \mathrm{C}$ и нагревали еще 13 ч. Через 4 ч с начала нагрева к реакционной смеси добавили 3 капли конц. $\mathrm{H}_{2} \mathrm{SO}_{4}$. По окончании реакционную массу обрабатывали диэтиловым эфиром $(9 \times 10$ мл). Полученную суспензию желто-коричневого цвета с белыми хлопьевидными частицами (соед. IV) фильтровывали, осадок промывали дистиллированной водой и оставляли сушиться на воздухе. Выход (IV сп. 1): 3.1 г (40\%). Светло-желтый аморфный порошок, т. пл. 302-304 ${ }^{\circ} \mathrm{C}$.

$N$-фенилимид малеопимаровой кислоты (IV) (способ 2) [12]. Смесь 2 г (5 ммоль) МПК и 0.5 мл (0.51 г, 5.5 ммоль) анилина в 20 мл толуола кипятили в течение 16 ч. По окончании раствор охлаждали до комнатной температуры для кристаллизации, осадок отфильтровывали и промывали в два этапа: сначала $(2 \times 15$ мл) толуола, затем (3 $\times 100$ мл) горячей дистиллированной воды. Осадок (соед. IV) сушили на воздухе. Выход (IV сп. 2): 1.87 г (80.0\%). Белый аморфный порошок, т. пл. 306-307 ${ }^{\circ} \mathrm{C}$.

2,2,3,3,4,4,5,5-Октафтор-1-амиловый эфир малеопимаровой кислоты (Va). Выход (Va): 2.18 г (71\%). Аморфный порошок светло-коричневого цвета, т. пл. $123-125^{\circ} \mathrm{C}$.

2,2,3,3,4,4,5,5,6,6,7,7-Додекафтор-1-гептиловый эфир малеопимаровой кислоты (Vб). Выход (Vб) 1.87 г (70\%). Маслообразный продукт светло-коричневого цвета. 
$N$-фенилимид 2,2,3,3,4,4,5,5-октафторамилмалеопимарата (VI a). 2 г (3.3 ммоль) эфира (Va) растворили в 25 мл толуола и добавили 0.33 мл (0.34 г, 3.6 ммоль) анилина. Смесь кипятили в течение 16 ч, после чего отделили образовавшийся $N$-фенилимид МПК (IV) (белый осадок) и отгоняли растворитель. Полученный продукт-сырец растворяли в 20 мл ДМФА, затем к раствору прилили 70 мл дистиллированной воды. Образовывавшийся хлопьевидный осадок бежевого цвета отделяли фильтрованием и промывали $(4 \times 20$ мл) теплой дистиллированной воды до прозрачных промывных вод, осадок сушили при $60{ }^{\circ} \mathrm{C}$ в течение 3 ч. Выход (VIa): 0.89 г (40\%). Бежевый аморфный порошок, т. пл. $188-190{ }^{\circ} \mathrm{C}$.

$N$-фенилимид 2,2,3,3,4,4,5,5,6,6, 7,7-додекафторгептилмалеопимарата (VIб). Методика получения аналогична синтезу (VIa) из 1.6 г (2.24 ммоль) эфира (Vб) и 0.23 мл (0.23 г, 2.46 ммоль) анилина в течение 10 ч. Выход (VІб) - 0.92 г (52\%). Бежевый порошок, т. пл. $162-165{ }^{\circ} \mathrm{C}$.

\section{Обсуждение результатов}

В настоящей работе изучены реакции абиетиновой кислоты (II) с $N$-фенилмалеимидом (ФМИ) (I) в расплаве в условиях кислотного катализа и полифторалкиловых эфиров малеопимаровой кислоты (Va, б) с анилином в толуоле.

$N$-Фенилимид (IV) синтезировали из абиетиновой кислоты и $N$-фенилмалеимида (I) по реакции ДильсаАльдера. Взаимодействие абиетиновой кислоты (II) с эквимольным количеством $N$-фенилмалеимида (I) проводили в расплаве при 90-100 ${ }^{\circ} \mathrm{C}$ в присутствии каталитических количеств концентрированной серной кислоты (рис. 1) в течение 15 ч, приняв за основу методику [20]. Реакционную массу обрабатывали диэтиловым эфиром, образовавшийся осадок отфильтровывали, промывали дистиллированной водой до нейтральной реакции и сушили на воздухе, выход продукта (IV сп. 1) составил $40 \%$.

Встречный синтез $N$-фенилимида малеопимаровой кислоты (IV) был проведен по известной методике [12] путем нагревания МПК (III) с анилином (рис. 1, табл. 1) в толуоле в течение 16 ч. При этом происходило выпадение белого осадка (продукт IV), который отделяли от раствора фильтрованием, промывали толуолом и водой и сушили на воздухе, выход (IV сп. 2) $80 \%$.

В УФ-спектрах полученных соединений (IV) проявляется максимум поглощения при 227 нм, соответствующий $\pi \rightarrow \pi^{*}$ переходу электронов, что свидетельствует о наличии кратной связи. Плечо низкой интенсивности при 264 нм принадлежит ароматическому фрагменту [18] (табл. 1).

В спектрах ЯMР ${ }^{1} \mathrm{H}$ соединений (IV) в диапазоне 7.11-7.49 м.д. присутствуют сигналы протонов бензольного кольца, протону у атома $\mathrm{C}^{14}$ соответствует сигнал с химическим сдвигом при 5.54 м.д.

Для синтеза полифторзамещенных $N$-фенилимидов малеопимаратов использовали 2,2,3,3,4,4,5,5-октафторамиловый (Va) и 2,2,3,3,4,4,5,5,6,6,7,7-додекафторгептиловый (Vб) эфиры, полученные по модифицированной методике [22] этерификацией МПК (III) эквимольным количеством спиртов-теломеров ( $n=2$ и 3 ) в условиях кислотного катализа (рис. 2, табл. 1).

$N$-Фенилимид 2,2,3,3,4,4,5,5-октафторпентилмалеопимарата (VIa) получали взаимодействием эфира (Va) с 10\%-м избытком анилина при кипячении в толуоле в течение 16 ч (рис. 2, табл. 1). Спустя 11 ч наблюдали выпадение белого осадка (до $10 \%$ ). По данным ЯМР ${ }^{1} \mathrm{H}$ выпавший осадок является $N$-фенилимидом малеопимаровой кислоты (IV), образовавшийся, возможно, в результате гидролиза сложноэфирной группы. Выход продукта (VIa) составил $40 \%$.

Синтез $N$-фенилимида 2,2,3,3,4,4,5,5,6,6,7,7-додекафторгептилмалеопимарата (VIб) проводили аналогично в толуоле путем взаимодействия эфира (Vб) с анилином (соотношение $1: 1.1$ ). Учитывая, что при получении соединения (VIa) через 11 ч наблюдался гидролиз сложноэфирной группы, время синтеза сокращено до 10 ч. Выделение соединения (VIa, б) проводили осаждением из раствора ДМФА добавлением воды. Соединение (VIб) получено с выходом 52\% (табл. 1).

Строение синтезированных соединений доказано спектральными методами. В спектрах ЯМР ${ }^{1} \mathrm{H}$ соединений (VIa, б) сохраняются сигналы протонов эфиров (Va, б) с химическими сдвигами: 4.61 (-O-CH $\left.2_{2}\right) ; 5.55$ $\left(\mathrm{C}^{14} \mathrm{H}\right) ; 6.09\left(-\mathrm{CF}_{2} \mathrm{H}\right)$ соответственно. Появляются сигналы протонов бензольного кольца в диапазоне $7.15-7.44$ м.д. (рис. 3 и 4$)$.

B спектре ЯMP ${ }^{19} \mathrm{~F}$ продуктов (VIa, б) наблюдаются сигналы, которые по химическим сдвигам, мультиплетности и интегральным интенсивностям соответствуют полифторалкильным фрагментам (табл. 2).

В ИК-спектрах имидов (VIa, б) имеются полосы валентных колебаний групп: -O-(C=O) при 1778 см$^{-1}$ и -N-(C=O) при 1707 см$^{-1}$, связи $\mathrm{C}-\mathrm{N}$ - при 1387 см$^{-1}$, связи C-F - в интервале 1300-1000 см ${ }^{-1}$ и колебания бензольного кольца - в диапазоне частот 1600-1447 см-1 (см. электронное приложение). 


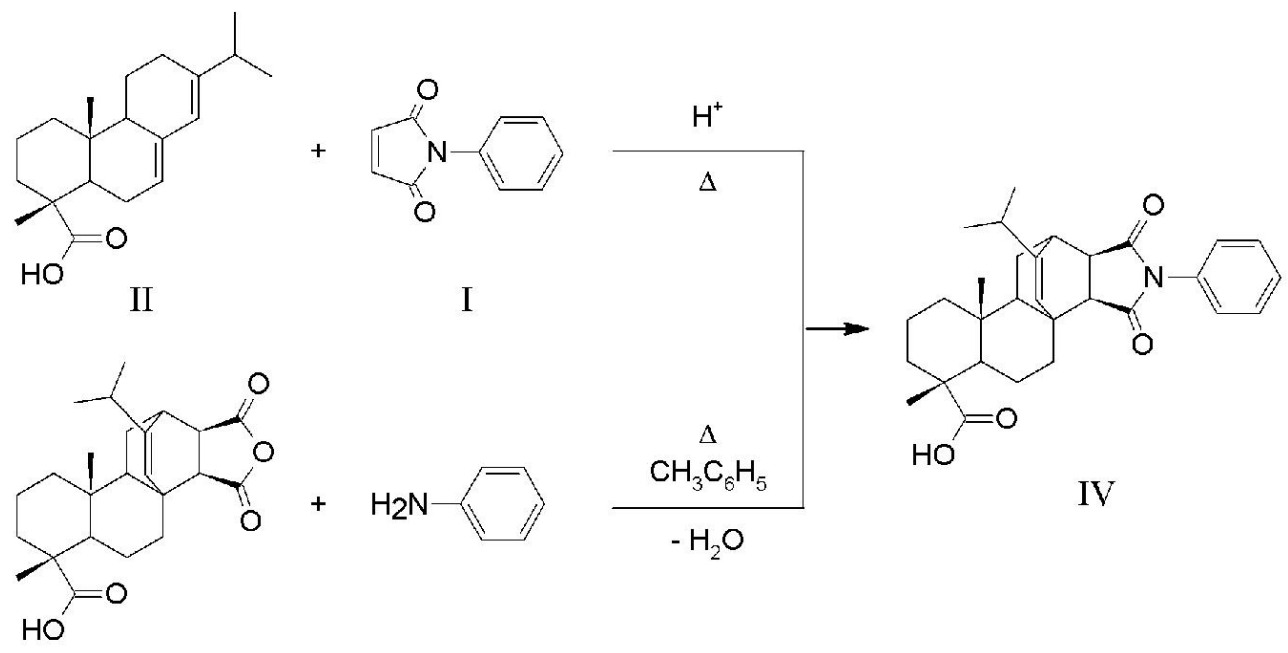

III

Рис. 1. Получение $N$-фенилимида малеопимаровой кислоты (IV)

Таблица 1. Выходы, температуры реакции, катализатор, продолжительность реакций, данные ТСХ, температуры плавления и УФ-спектры $N$-фенилимидов МПК (IV), 2,2,3,3,4,4,5,5-октафторамил (Va) и $2,2,3,3,4,4,5,5,6,6,7,7$-додекафторгептилмалеопимаровых кислот (Vб), $N$-фенилимидов 2,2,3,3,4,4,5,5-октафторамил- (VI a) и 2,2,3,3,4,4,5,5,6,6,7,7-додекафторгептилмалеопимаровых кислот (VIб)

\begin{tabular}{|c|c|c|c|c|c|c|c|}
\hline $\begin{array}{c}\text { Шифр } \\
\text { соедния }\end{array}$ & $\begin{array}{c}\text { Выход, } \\
\%\end{array}$ & $\mathrm{~T}_{\mathrm{p} \text {-ции, }}{ }^{\circ} \mathrm{C}$ & $\begin{array}{c}\text { Катализа- } \\
\text { тор }\end{array}$ & $\tau_{\text {р-ции, }}$, & $\mathrm{R}_{\mathrm{f}}$ & Т.пл., ${ }^{\circ} \mathrm{C}$ & $\begin{array}{c}\lambda_{\max }, \mathrm{HM} \\
(\lg \varepsilon)\end{array}$ \\
\hline IV (сп. 1) & 40 & 100 & $\mathrm{H}_{2} \mathrm{SO}_{4}$ & 15 & 0.33 & $302-304$ & $\begin{array}{c}227 \text { (4.10) } \\
264 \text { (пл.) }\end{array}$ \\
\hline IV (сп. 2) & 80 & 110 & - & 16 & 0.33 & $305-307$ & $\begin{array}{c}227 \text { (3.81) } \\
264 \text { (пл.) }\end{array}$ \\
\hline $\mathrm{V} \mathrm{a}$ & 71 & $135-140$ & $\mathrm{H}_{2} \mathrm{SO}_{4}$ & 6 & 0.40 & $123-125$ & $225(3.38)$ \\
\hline V б & 70 & $165-170$ & $\mathrm{H}_{2} \mathrm{SO}_{4}$ & 6 & 0.47 & масло & $\begin{array}{l}226(3.35) \\
237(3.23)\end{array}$ \\
\hline VI a & 40 & 110 & - & 16 & 0.25 & $188-190$ & $227(3.48)$ \\
\hline VI 6 & 52 & 110 & - & 10 & 0.20 & $162-165$ & $227(3.79)$ \\
\hline
\end{tabular}

Примечание. IV (сп.1) получен из II и I; IV (сп.2) - из III с анилином.

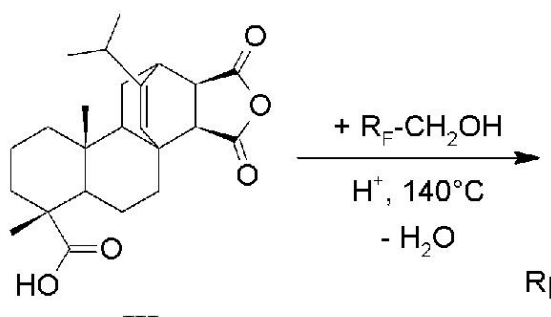

III

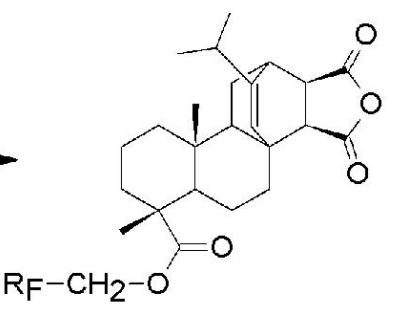

$\mathrm{V}$ a, $\sigma$

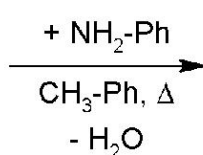<smiles>[R7]COC(=O)CC</smiles>

VI a, 6

$\mathrm{R}_{\mathrm{F}}=\mathrm{CF}_{2} \mathrm{CF}_{2} \mathrm{CF}_{2} \mathrm{CF}_{2} \mathrm{H}(\mathrm{a}), \mathrm{CF}_{2} \mathrm{CF}_{2} \mathrm{CF}_{2} \mathrm{CF}_{2} \mathrm{CF}_{2} \mathrm{CF}_{2} \mathrm{H}(\bar{\sigma})$

Рис. 2. Получение $N$-фенилимидов полифторалкилмалеопимаратов (VIa, б) 


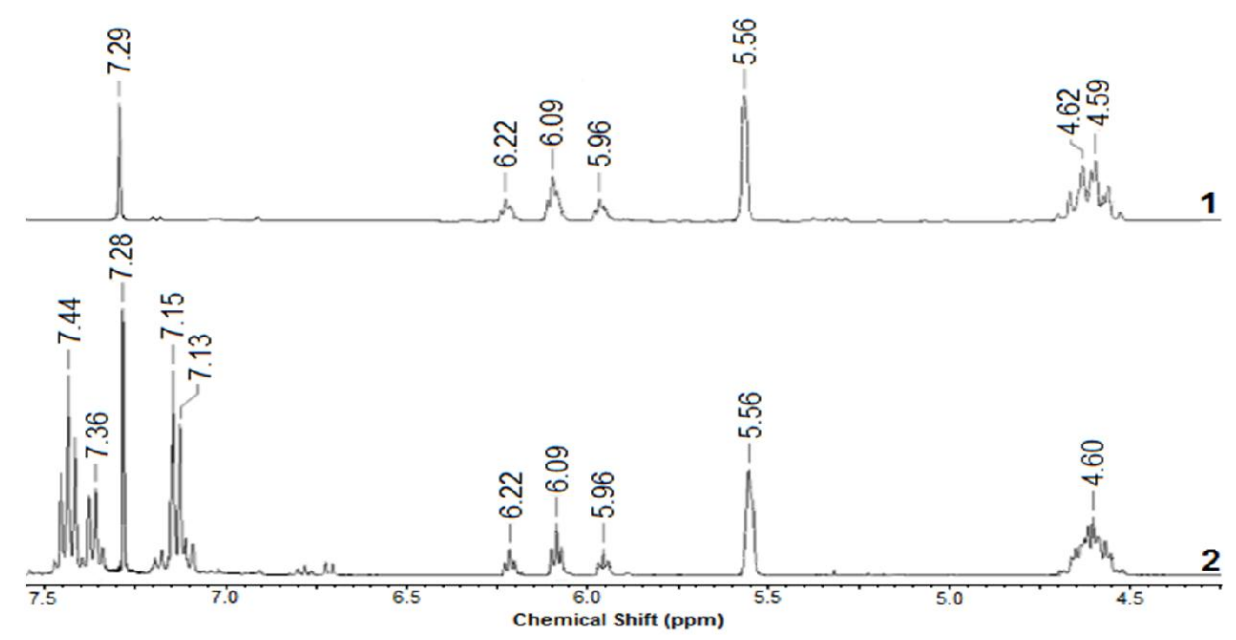

Рис. 3. ЯМР ${ }^{1} \mathrm{H}$ спектры 1 - 2,2,3,3,4,4,5,5-октафтор-1-амиловый эфир малеопимаровой кислоты (Va); 2 - N-фенилимид 2,2,3,3,4,4,5,5-октафторамилмалеопимаровой кислоты (VIa)

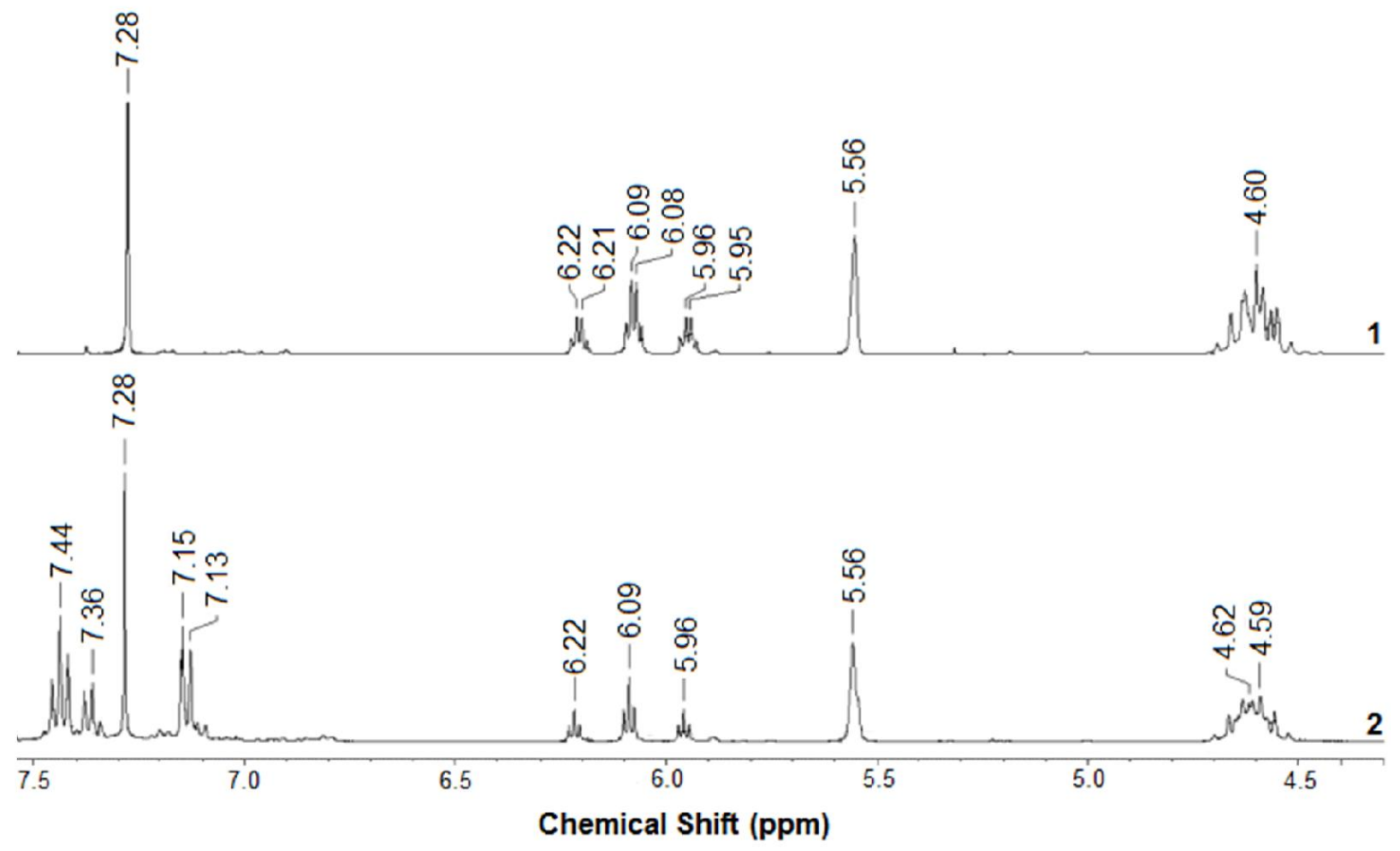

Рис. 4. ЯМР ${ }^{1} \mathrm{H}$ спектры 1 - 2,2,3,3,4,4,5,5,6,6,7,7-додекафтор-1-гептиловый эфир малеопимаровой кислоты (Vб); 2 - N-фенилимид 2,2,3,3,4,4,5,5,6,6,7,7-додекафторгептилмалеопимаровой кислоты (VIб)

Таблица 2. Данные ЯMP ${ }^{19} \mathrm{~F}$ спектроскопии 2,2,3,3,4,4,5,5-октафторамил - (Va) и 2,2,3,3,4,4,5,5,6,6,7,7додекафторгептилмалеопимаровых кислот (Vб), $N$-фенилимидов 2,2,3,3,4,4,5,5-октафторамил (VIa) и 2,2,3,3,4,4,5,5,6,6,7,7-додекафторгептилмалеопимаровых кислот (VIб)

\begin{tabular}{|c|c|c|c|c|}
\hline $\begin{array}{c}\text { Шифр } \\
\text { соединения }\end{array}$ & $\mathrm{Va}$ & Vб & VIa & VІб \\
\hline $\begin{array}{c}\left(\mathrm{CDCl}_{3}\right) \delta, \\
\text { м.д. }\end{array}$ & $\begin{array}{l}-137,18 \text { (д } J 51,82 \text { Гц, } 2 \mathrm{~F}, \\
\left.\mathrm{CHF}_{2}\right) ;-129,87 \text { (с } 2 \mathrm{~F}, \\
\left.\mathrm{C}^{2} \mathrm{~F}_{2}\right) ;-125,18(\text { с } 2 \mathrm{~F}, \\
\left.\mathrm{C}^{3} \mathrm{~F}_{2}\right) ;-119,55(\text { с } 2 \mathrm{~F}, \\
\left.\mathrm{C}^{4} \mathrm{~F}_{2}\right)\end{array}$ & $\begin{array}{l}-137,05 \text { (д J 52,00 Гц, } \\
\left.2 \mathrm{~F}, \mathrm{C}^{7} \mathrm{HF}_{2}\right) ;-129,34(\mathrm{c} \\
\left.2 \mathrm{~F}, \mathrm{C}^{6} \mathrm{~F}_{2}\right) ;-123.34(\mathrm{c} \\
\left.4 \mathrm{~F} ; \mathrm{C}^{4} \mathrm{~F}_{2}-\mathrm{C}^{5} \mathrm{~F}_{2}\right) ;-122,15 \\
\left(\mathrm{c} 2 \mathrm{~F}, \mathrm{C}^{3} \mathrm{~F}_{2}\right) ;-119,35(\mathrm{c} \\
\left.2 \mathrm{~F}, \mathrm{C}^{2} \mathrm{~F}_{2}\right)\end{array}$ & $\begin{array}{l}-137,15 \text { (д J53,67 Гц, } \\
\left.2 \mathrm{~F}, \mathrm{C}^{5} \mathrm{HF}_{2}\right) ;-129,91 \\
\left(\text { c } 2 \mathrm{~F}, \mathrm{C}^{4} \mathrm{~F}_{2}\right) ;-125,17 \\
\left(\text { c } 2 \mathrm{~F}, \mathrm{C}^{3} \mathrm{~F}_{2}\right) ;-119,53 \\
\left(\text { c } 2 \mathrm{~F}, \mathrm{C}^{2} \mathrm{~F}_{2}\right)\end{array}$ & $\begin{array}{l}-137,05 \text { (д J 51,77 Гц, } \\
\left.2 \mathrm{~F}, \mathrm{C}^{7} \mathrm{HF}_{2}\right) ;-129,36(\mathrm{c} \\
\left.2 \mathrm{~F}, \mathrm{C}^{6} \mathrm{~F}_{2}\right) ;-123,34(\mathrm{c} \\
\left.4 \mathrm{~F}, \mathrm{C}^{4} \mathrm{~F}_{2}-\mathrm{C}^{5} \mathrm{~F}_{2}\right) ;-122,15 \\
\left(\mathrm{c} 2 \mathrm{~F}, \mathrm{C}^{3} \mathrm{~F}_{2}\right) ;-119,34(\mathrm{c} \\
\left.2 \mathrm{~F}, \mathrm{C}^{2} \mathrm{~F}_{2}\right) .\end{array}$ \\
\hline
\end{tabular}




\section{Выводы}

1. Впервые синтезированы $N$-фенилимиды полифторалкиловых эфиров малеопимаровой кислоты взаимодействием соответствующих монозамещенных полифторсодержащих малеопимаратов с анилином при кипячении в толуоле в течение 10-16 ч с выходами от 40 до 52\%.

Установлено, что увеличение времени реакции (более 11 ч) приводит к гидролизу сложноэфирной связи и образованию $N$-фенилимида малеопимаровой кислоты.

2. Показано, что взаимодействие абиетиновой кислоты с $N$-фенилмалеимидом в расплаве в присутствии каталитических количеств концентрированной $\mathrm{H}_{2} \mathrm{SO}_{4}$ в течение 15 ч приводит к образованию соответствующего $N$-фенилимида малеопимаровой кислоты, но с более низким выходом (40\%).

\section{Список литературы}

1. Зандерманн В. Природные смолы, скипидары, талловое масло. М., 1964. 576 с.

2. Patent 2011303376 (US). Imidized and amidized rosin compositions for paper sized and other applications / Piasmine Technology. 2011.

3. Бей М.П., Азарко В.А., Ювченко А.П. Синтез, пленкообразующие и светочувствительные свойства аллиловых и пропаргиловых эфиров малеопимаровой и цитраконопимаровой кислот // Журнал органической химии. 2000. Т. 80, вып. 5. С. 770-773.

4. Толстиков Г.А., Толстикова Т.Г., Шульц Э.Э., Толстиков С.Е., Хвостов М.В. Смоляные кислоты хвойных России. Химия, фармакология. Новосибирск, 2011. 396 с.

5. Rosin - based Chemicals and Polymers. Ed. by Jinwen Zhang. Shawbury, Shewsbury, Shropshire: Smithers Rapra Technology Ltd., 2012. 234 p.

6. А.c. 543252 (СССР). Производные $\mathrm{N}$-замещенных имидов малеопимаровой кислоты, проявляющие фунгицидную активность, и способы их получения / Д.Я. Свикле, А.Я. Калниньш, Р.Я. Карклинь, А.Я. Прикуле, Б.А. Прусе, А.А. Румба, Г.К. Баумане, Р.А. Расиня, Д.Ф. Швинска, А.Я. Кулькевиц. 1977.

7. Yao G., Ye M., Huang R., Li Y., Zhu Y., Pan Y., Liao Z., Wang H. Synthesis and antitumor activity evaluation of maleopimaric acid N-aryl imide atropisomers // Bioorganic \& medical chemistry Letters. 2013. Vol. 23. Pp. 6755-6758. DOI: $10.1016 /$ j.bmcl.2013.10.028.

8. Patent 31355749 (FR). Imido-maleopimaric acid unsaturated derives. for use in copolymers with vinyl-chloride, giving improved heat and shock resist / Inst Du Pin. 1973.

9. Patent $101812173(\mathrm{CN})$. N-hydroxy maleopimaric acid imide ester acetal polymer and pre-paration method thereof / L. Wang, X. Zhai. 2010.

10. Абэ Т., Нагасэ С. Соединения фтора: Синтез и применение. М., 1990. 407 с.

11. Патент 1761749 (СССР). Способ получения $N$-(n-карбоксифенилен)имида малеопимаровой кислоты / Э.Ф. Буйнова, А.П. Солнцев, А.И. Воложин. 1992.

12. Sandermann W., Striesow K. Reduktion von Dienaddukten der Lävopimarsäure und Anderer Verbindungen mit Lithiumaluminiumhydrid // Chemische Berichte. 1957. Jg. 90, N5. S. 693-698.

13. Бей М.П., Ювченко А.П. Синтез новых амидов и имидов малеопимаровой кислоты // Весці Нац. Акад. навук Беларусі. Сер. хім. навук. 2010. №1. С. 74-78.

14. Bei M.P., Yuvchenko A.P., Puchkova N.V. Efficient synthesis of maleopimaric acid N-arylimides // Russ. J. Gen. Chem. 2015. Vol. 85, N85. Pp. 1034-1039. DOI: 10.1134/S1070363215050047.

15. Патент 2591193 (RU). Способ получения имидов метилового эфира малеопимаровой кислоты / И.М. Сахаутдинов, Р.Н. Маликова, Ю.В. Вахитова, О.В. Закирьянова, А.А. Фатыхов, М.С. Юнусов. 2015.

16. Patent 122058 (GB). Improvements in or relating to processes of preparing resinous products / Hercules Incorporated. 1971.

17. Бей М.П. Синтез новых кислород- и азотсодержащих производных малеопимаровой кислоты: автореф. дис. ... канд. хим. наук. Минск. 2015. 25 с.

18. Гордон А., Форд Р. Спутник химика: справочник. М., 1976. 542 с.

19. Лазурьевский Л.В., Терентьева И.В., Шамшурин А.А. Практические работы по химии природных соединений. M., $1961.192 \mathrm{c}$.

20. А.с. 235046 (СССР). Способ получения аддуктов смоляных кислот или канифоли с малеиновым ангидридом / Ю.Я. Добелис, Д.Я. Свикле, Я.Г. Зандерсон, А.И. Калниньш. 1969.

21. Максимов Б.Н., Барабанов В.Г., Серушкин И.Л., Зотиков В.С., Семерикова И.А. Степанов В.П., Сагайдакова Н.Г., Каурова Г.И. Справочник. Промышленные фторорганические продукты. СПб., 1996. 544 с.

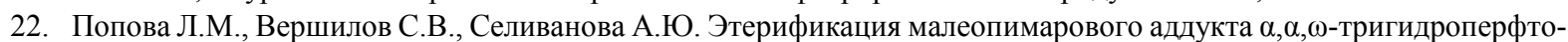
ралканолами // Химия растительного сырья. 2014. №1. С. 73-76. DOI: 10.14258/jcprm.1401073.

$$
\begin{array}{r}
\text { Поступила в редакииюю } 14 \text { апреля } 2018 \text { г. } \\
\text { После переработки } 5 \text { декабря } 2018 \text { г. } \\
\text { Принята к публикации } 12 \text { января } 2019 \text { г. }
\end{array}
$$

Для цитирования: Попова Л.М., Иванова В.А., Вершилов С.В. Синтез N-фенилимидов полифторалкиловых эфиров малеопимаровой кислоты // Химия растительного сырья. 2019. №2. С. 205-211. DOI: $10.14258 /$ jcprm.2019023999. 
Popova L.M..$^{*}$, Ivanova V.A. ${ }^{1}$, Vershilov S.V. ${ }^{2}$ SYNTHESES OF POLYFLUOROALKYL ESTERS OF MALEOPIMARIC ACID N-PHENYLIMIDE

${ }^{1}$ Saint Petersburg State University of Industrial Technology and Design, Graduate School of Technology and Energy,

Ivana Chernykh, 4, St. Petersburg, 198095 (Russia), e-mail: lorapopova@mail.ru

${ }^{2}$ Research Institute for Synthetic Rubber Acad. S.V. Lebedev, Gapsalskaya, 1, St. Petersburg, 198035 (Russia)

To meet the challenge of complex processing of plant material, in particular, tall oil rosin, research has been conducted on the synthesis of new polyfluroalkyl maleimides. As is well known, maleopimaric acid's imides constitute a forward-looking class of organic compounds for pharmacology, agriculture, polymer chemistry and so on. The introduction of a fluorocarbon unit often gives high surface activity, chemical and heat resistance, hydrophobic and oleophobic properties. This paper presents the results of experiments on the synthesis of new N-phenylimides of maleopimaric acid's polyfluoroalkyl esters by the interaction of the corresponding monosubstituted polyfluorinated maleopimarates with aniline during boiling for $10-16 \mathrm{~h}$ in toluene (40-52\%). The starting N-phenylimide of maleopimaric acid has been obtained by two methods: by the Diels-Alder reaction from abietic acid and N-phenyl maleimide using sulfuric acid as a catalyst in the melt (40\%) and by heating (MPA) with aniline in toluene (80\%). 2,2,3,3,4,4,5,5-octafluoroamyl and 2,2,3,3,4,4,5,5,6,6,7,7,7- dodecaftaforpetyl ethers have been obtained by esterification of MPA with fluorinated alcohols under conditions of acid catalysis (70\%). It have been identified the ester bonds are quite stable by TLC during long-term treatment of the stock (over 11 hours). The synthesized substances were analyzed with UV-, IR-, 1H NMR and 19F.

Keywords: N-phenylimides, abietic acid, maleopimaric acid, N-phenylimides polyfluoroalkyl esters of malepimaric acid.

\section{References}

1. Zandermann V. Prirodnyye smoly, skipidary, tallovoye maslo. [Natural resins, turpentine, tall oil]. Moscow, 1964, 576 p. (in Russ.).

2. Patent 2011303376 (US). 2011.

3. Bey M.P., Azarko V.A., Yuvchenko A.P. Zhurnal organicheskoy khimii, 2000, vol. 80, issue 5, pp. 770-773. (in Russ.).

4. Tolstikov G.A., Tolstikova T.G., Shul'ts E.E., Tolstikov S.Ye., Khvostov M.V. Smolyanyye kisloty khvoynykh Rossii. Khimiya, farmakologiya. [Resin acids coniferous Russia. Chemistry, pharmacology]. Novosibirsk, 2011, 396 p. (in Russ.).

5. Rosin - based Chemicals and Polymers. Ed. by Jinwen Zhang. Shawbury, Shewsbury, Shropshire: Smithers Rapra Technology Ltd., 2012. 234 p.

6. Certificate of Authorship 543252 (USSR). 1977. (in Russ.).

7. Yao G., Ye M., Huang R., Li Y., Zhu Y., Pan Y., Liao Z., Wang H. Bioorganic \& medical chemistry Letters, 2013, vol. 23, pp. 6755-6758. DOI: 10.1016/j.bmcl.2013.10.028.

8. Patent 31355749 (FR). 1973.

9. Patent $101812173(\mathrm{CN}) .2010$.

10. Abe T., Nagase S. Soyedineniya ftora: Sintez i primeneniye. [Fluorine compounds: Synthesis and application]. Moscow, 1990, 407 p. (in Russ.).

11. Patent 1761749 (USSR). 1992. (in Russ.).

12. Sandermann W., Striesow K. Chemische Berichte, 1957, Jg. 90, no. 5, s. 693-698. (in German).

13. Biej M.P., Juvčjenko A.P. Viesci Nac. Akad. navuk Bielarusi. Sier. chim. navuk., 2010, no. 1, pp. 74-78.

14. Bei M.P., Yuvchenko A.P., Puchkova N.V. Russ. J. Gen. Chem., 2015, vol. 85, no. 85, pp. 1034-1039. DOI: $10.1134 / \mathrm{S} 1070363215050047$.

15. Patent 2591193 (RU). 2015. (in Russ.).

16. Patent 122058 (GB). 1971.

17. Bey M.P. Sintez novykh kislorod- $i$ azotsoderzhashchikh proizvodnykh maleopimarovoy kisloty: avtoref. dis. ... kand. khim. nauk. [Synthesis of new oxygen- and nitrogen-containing derivatives of maleopimaric acid: abstract of the dissertation of the candidate of chemical sciences]. Minsk, 2015, 25 p. (in Russ.).

18. Gordon. A., Ford R. Sputnik khimika: Spravochnik. [Chemist's Satellite: A Handbook]. Moscow, 1976, 542 p. (in Russ.).

19. Lazur'yevskiy L.V., Terent'yeva I.V., Shamshurin A.A. Prakticheskiye raboty po khimii prirodnykh soyedineniy. [Practical work in the chemistry of natural compounds]. Moscow, 1961, 192 p. (in Russ.).

20. Certificate of Authorship 235046 (USSR). 1969. (in Russ.).

21. Maksimov B.N., Barabanov V.G., Serushkin I.L., Zotikov V.S., Semerikova I.A. Stepanov V.P., Sagaydakova N.G., Kaurova G.I. Promyshlennyye ftororganicheskiye produkty. Spravochnik. [Industrial organofluorine products. Directory.]. St. Petersburg, 1996, 544 p. (in Russ.).

22. Popova L.M., Vershilov S.V., Selivanova A.YU. Khimiya rastitel'nogo syr'ya, 2014, no. 1, pp. 73-76. DOI: 10.14258/jcprm.1401073 (in Russ.).

Received April 14, 2018

Revised December 5, 2018

Accepted January 12, 2019

For citing: Popova L.M., Ivanova V.A., Vershilov S.V. Khimiya Rastitel'nogo Syr'ya, 2019, no. 2, pp. 205-211. (in Russ.). DOI: $10.14258 /$ jeprm.2019023999.

\footnotetext{
${ }^{*}$ Corresponding author.
} 
